\title{
PERO ME GUSTA LO BUENO, UNA LECTURA ÉTICA DE LOS CORRIDOS QUE HABLAN DEL NARCOTRÁFICO Y DE LOS NARCOTRAFICANTES MARÍA LUISA DE LA GARZA CHÁVEZ PORRÚA, UNICACH, MÉXICO, 2008
}

Fabio Alexis de Ganges López viajealasemilla@hotmail.com

CESMECA-UNICACH

México

Con este libro, María Luisa de la Garza ha realizado una lectura profunda, analítica y además amena - en ocasiones con toques de humor- de los narcocorridos. Se trata además de un análisis enriquecedor y al mismo tiempo enriquecido por diversas perspectivas, pero sin perder de vista su principal elemento guía -mencionado desde el subtítulo e insinuado en la cita que da nombre al texto: «pero me gusta lo bueno»—: la ética inserta en este tipo de composiciones culturales.

Como se dice en el prólogo, la muestra ha sido de más de 600 corridos de «oralidad secundaria» — grabaciones discográficas — y su inspiración metodológica la filosofía de Paul Ricoeur, cuya teoría hermenéutica no es indiferente a producciones culturales y cuya ética atañe también a las instituciones y a un ideal de esta índole ante situaciones prácticas. También porque en las ideas de Ricoeur hay una fenomenología acerca de capacidades e incapacidades en las expresiones modales puedo/no puedo. Por último porque esta filosofía concibe todo decir público como acto político.

Antes de iniciar su análisis - estructurado en seis capítulos que analizan distintas cuestiones insertas en estas composiciones: la realización personal, los patrones de excelencia, las relaciones interpersonales, la relación con las fuerzas del Estado, el orden social y la relación con Estados Unidos_-, la autora hace algunas aclaraciones y explica sus objetivos. Comenta que los narcocorridos se han estudiado desde perspectivas 
sociológicas, desde los estudios culturales, la etnomusicología, la antropología urbana, y añade:

La presente obra se inserta en este espectro de análisis y reflexión, pero desde una perspectiva filosófica. Trata de las representaciones sociales que ponen en juego los corridos de narcotráfico, interesándose en particular en la ética que sustenta las relaciones interpersonales y sociales que presentan. Esto permite repensar el carácter «inmoral» $\mathrm{y}$ «subversivo» de unas canciones que no solo exaltan a unos personajes de quienes lo más desconcertante quizá sea que, a diferencia de la mayoría de los mexicanos, parecen realizados y felices, sino que además reflexionan y juzgan al sistema político, social y de procuración de justicia de México, planteando una serie de dilemas prácticos que son pertinentes para el conjunto de las sociedad y que, a pesar de lo que pareciera, no se resuelven de una única manera (pp. 7-8).

El primer capítulo, «De la vida buena a la buena vida» habla del ideal de vida de los personajes en los narcocorridos. Hay cinco bienes muy preciados: mujeres, recursos económicos, independencia, tiempo de ocio festivo y el reconocimiento de los demás. Naturalmente es posible resumir todo esto en uno solo: dinero. En cambio ser pobre es, como se afirma en el corrido El bucanero, «la pobreza es el infierno, ya lo pude comprobar, y desde que entré al negocio la gloria empecé a gozar: dinero, vino y mujeres me sobran pa'pachanguear» (p. 12).

El entrar de narcotraficante representa un cambio de vida radical y una opción más deseable que irse de mojado. Aunque implique riesgos vale la pena. Para los narcocorridos es reivindicable gozar de la vida, aunque no se busque trasformar el sistema social. Entrar en el narcotráfico es tener poder para cambiar el curso de la vida propia. Semánticamente hay un antes - humillaciones, penas, pobrezas-y un después mujeres, peticiones de favores, dinero, lujo, fiestas-. Los personajes amplían su capacidad de poder-tener, poder-hacer y hasta poder-ser. La autora sugiere que el verbo pasear se repite en varios corridos. Los personajes pueden moverse impunemente y además relacionarse con todos los ámbitos sociales. Hay un cierto clasismo y además se 
sugiere que sólo puede aquel que tiene. De esta manera en algunos corridos que se dicen «perrones», como en El padre de los cabrones, el personaje lo que impone más que respeto es temor. En estos corridos también se sugiere el cumplimiento de los deseos aun con indiferencia hacia los otros.

Los corridos, como ya había sugerido la autora en su libro Ni aquí, ni allá, suelen ser individualistas y los narcocorridos no son la excepción. Se busca prestigió y fama y se hace alusión a las inclinaciones naturales — «Ya pólvora trae mi sangre», dice el personaje de El primo —. También se da importancia a la suerte y al destino. Incluso llega a darse como natural el narcotráfico y el consumo de cocaína. Sólo en unos cuantos ejemplos los personajes deciden dar un cambio a su vida y «cerrar el changarro», como en Las pompis de mi güera.

El título del capítulo dos, «Todos tienen de lo bueno porque les doy lo mejor», se refiere a que en los corridos se hace referencia constante a patrones de excelencia que tienen que ver con el mundo de los negocios. La idea es que el ámbito de lo ilegal se guía por patrones de excelencia similares a los de esferas legitimadas. Así, numerosas letras de narcocorridos hablan de lo que se ofrece a los clientes, tanto en calidad como en eficiencia. Son los narcotraficantes los únicos que parecen progresar y modernizarse.

Sugiere la autora que tres son los rasgos de personalidad que más destacan en estos corridos: la valentía, la astucia y tener palabra. Sin embargo, estas cualidades dependen del contexto, pues a veces se convierten estos valores en «antivalores». Lo valiente, por ejemplo, más que un desprecio a la vida se convierte en un desprecio a la muerte.

Viene en roca cristalina la cantidad que ordenó.

Si el mercado es exigente complacidos serán hoy, el cártel que la fabrica le ha estampado un escorpión (p. 50). 
Los personajes hacen alarde de ser buenos administradores, tener equipos eficientes, así como de utilizar las tecnologías más avanzadas.

Un rasgo que complementa lo valiente es la astucia, y los personajes tienen muchas mañas y astucias para burlar la ley y pelarse cuando sea necesario. Pero a pesar de esto son derechos o legales aunque, como explica la autora: «Ser derechos en este contexto significa, sobre todo, cumplir la palabra dada. Ahora bien, no es la palabra empeñada en una promesa, sino la que forma parte de un acuerdo, de un pacto, casi siempre mediado por el dinero» (p. 64). Así, por miedo a represalias o acuerdos de conveniencia mutua es posible confiar en quienes han tenido un trato económico con uno. Sin embargo, aquel que no es derecho queda en riesgo de que se cumplan las amenazas contra su vida, como en el ejemplo del corrido El jefazo, en donde se dice de quien no quiso entrarle a un trato: «Ya está muerto el comandante porque no aceptó la oferta: no traicionó el reglamento, pero la vida le cuesta» (p. 66).

«No te fíes de los halagos, ni siquiera de pariente» es el título del tercer capítulo y comienza con una mención a la conocida cita de Hobbes en Leviatán: «El lobo es el lobo del hombre» . En el mundo de los narcocorridos no es posible fiarse de nadie. Por doquier están tres pasiones primitivas: competencia, desconfianza y deseo de gloria. A pesar de esto hay algo que está por encima incluso de la propia vida: la familia, con la que se trabaja y hacia la que hay una completa lealtad. En cambio las mujeres apenas con consideradas objetos y solo hay obligación con las esposas. También los compadres son importantes porque son considerados casi como hermanos. Por otra parte es fácil desconfiar de los amigos porque las relaciones, al estar basadas en el interés monetario, son muy frágiles. El otro motivo para desconfiar de alguien es la envidia. La amistad entonces se dirige a armas y coches. Además, un amigo será considerado realmente sincero hasta el final de la vida, cuando la amistad quedó al fin demostrada. 
La parranda es el sitio óptimo para estar con los amigos, pues es entre el alcohol y la música como los personajes se sienten en confianza. En otro sentido, las relaciones en el narcotráfico se dan de abajo para arriba. Además hay que compartir y ser sencillo, porque

este deber de compartir tiene una significación que rebasa lo que sería una simple estrategia de protección o defensa frente a las deslealtades, y de lo que serían también, en este contexto, buenas maneras ... Es común a todos los corridos norteños contemporáneos, sean de narcotráfico, de migración o de política, una cierta obligación de que una persona o un solo grupo no acapare todos los bienes materiales, como si por ser tan fortuito el éxito debiera compartirse con los menos afortunados (p. 85).

Por último la autora hace un recuento de corridos que van contra el imperativo kantiano de usar a la humanidad como un fin y no solo como un medio. En ocasiones los narradores, más allá de defender al perseguido — pues, como sugiere Guillermo Hernández, los corridos han apoyado siempre al perseguido- se solidarizan con personajes extremadamente violentos, como en el corrido El gran jefe (el Mayel), que relata el caso de Ismael Higuera Guerrero, del cártel de los hermanos Arellano Félix — apodado El ejecutor por las autoridades.

El capítulo cuatro se titula «Que llegaron federales para acabar con los narcos». Casi siempre en los narcocorridos se da la relación entre «yo, narcotraficante» y «ellos», las fuerzas del Estado. Se intenta hacer ver que los judiciales tienen menos autoridad y que los narcos tienen poder para comprar sus voluntades con «unos verdes». Así, son incluso sus benefactores. Además, como en La jefa — «es una hembra muy brava que ha matado a mucha gente: tres policías, seis soldados y, de pilón, un teniente»- (p. 100) matar policías es como un trofeo.

La autora expone que la oposición de narcotraficantes contra representantes de la ley se convierte, por medio de la corrupción, en la ley contra narcos y autoridades corruptas. 
Así, desconfiar de las instituciones ha dado lugar a «la cooperación», la cual es darle al otro lo que necesita en ese momento - como en los corridos El judicial y el traficante y La Suburban dorada-. Además hay otros tipos de prácticas corruptas, como sugiere el corrido La merma del traficante — «con 20 kilos de nieve, cada kilo en una bolsa, un comandante a su jefe sólo 15 le reporta»—- (p. 103). La conclusión al final del capítulo da para pensar:

En los corridos de narcotráfico, como en la tradición filosófica que va desde Aristóteles hasta Rawls, se identifica la justicia con la justicia distributiva, aunque el «reparto compensatorio» que estos textos plantean esté muy alejado del «dar a cada uno lo suyo», porque «lo suyo», si el reparto es contingente, permanece sin posibilidad de ser definido (p. 110).

El capítulo cinco, que lleva por título «Ya mi tierra tiene fama de secuestros y bandidos», habla del orden social en general y de las relaciones con los personajes y el Estado. Se dice que a fin de cuentas «los grandes» del narcotráfico y la política son «ramas del mismo árbol». Es en 1969 cuando se hace público que algunos funcionarios estaban involucrados con el narcotráfico, y en 1985 empezaron a mencionarse nombres de gobernadores, policías y otros altos funcionarios relacionados con el narco. Esto pasó a los narcocorridos, como en El circo, de Los tigres del norte, en donde se critica a Carlos Salinas de Gortari, ex presidente de la República. En los corridos hay una distinción entre el pueblo y los políticos, estos son vistos todos como «sinvergüenzas» y «ladrones».

En cuanto a la procuración de justicia, los narradores de los narcocorridos se muestran totalmente escépticos. Así, se sugiere que solamente los peces grandes, que tienen dinero, pueden pagar su libertad, mientras que las prisiones están llenas de «los de abajo». En cuanto a los más grandes solo los agarran muertos, como se dice en «El señor de los cielos» respecto de Amado Carrillo Fuentes. Sin embargo, los corridos hablan también de policías honestos, cuyo cumplimiento del deber y sacrificio es, a fin de cuentas, en vano, como se dice en los versos de Por debajo del agua, en donde un judicial muere pero la 
droga es entregada a tiempo. En este sentido se sugiere que al menos se evite un inútil derramamiento de sangre y que los judiciales no se hagan los valientes. Así, como explica José Manuel Valenzuela (2007) en Jefe de jefes, corridos y narcocultura en México, hay una imposición de la cultura del miedo y el narcotráfico. Aunque como agrega la autora, «habrá que colocarlos [los corridos] en su contexto discursivo, para reconsiderarlos como lo que también son: una forma de participación en el debate público, puesto que no debemos olvidar que son discursos que se hacen circular y que se llevan a escena» (p. $132)$.

María Luisa de la Garza sigue un estudio de Axel Honnet sobre el reconocimiento jurídico

${ }^{1}$ para adentrarse en la manera en que se reivindica el poder de un arma ante una ausencia de una justicia social equitativa. En este sentido los narcotraficantes entran en el negocio para poder tener no solo dinero, sino también para poder ser alguien. Al comparar la representación social de los narcotraficantes con el análisis de Fernando Escalante de las comunidades campesinas del siglo XIX se encuentran tres rasgos: el deber de «cooperarse», distancia respecto a autoridades formales y ausencia de prácticas cívicas.

El sexto y último capítulo: «No quieren que exista droga, pero se dan privilegios», aborda el tema de la relación con Estados Unidos. Los desacuerdos entre México y su vecino del norte en materia de narcotráfico aparecen en varios corridos. Así hay algunos a la «certificación» o colaboración de México y otros países en la lucha contra las drogas. También hay referencias a la «Operación Casa Blanca», para contrarrestar el lavado de dinero.

Aunque en Estados Unidos se pretenda echar la culpa a otros países ellos demandan droga, como dice el corrido El rey de cristal: «Mis clientes más grandes son mis amigos los gringos, nomás que juegan la parte, pero ellos son los macizos». Otros corridos sugieren que Estados Unidos se guía por el dinero para sus políticas y sólo ve lo que le 
parece conveniente. Así se habla de funcionarios corruptos de la DEA o del soborno a los agentes fronterizos — «El carril número tres».

Vender droga en Estados Unidos es visto como algo satisfactorio, denota una buena calidad de los productos mexicanos y además implica enmendar las ofensas a México. Sin embargo esto parece tener, actualmente, más que ver con el prestigio de exportar productos de calidad que con no afectar al propio entorno. Así:

\begin{abstract}
Cuando los corridos ponen énfasis en la representación social de los narcotraficantes como empresarios, «ellos, los estadounidenses», son, sobre todo, «los importadores», «los compradores», «los grandes consumidores», y «nosotros, los mexicanos», quienes «les vendemos», o sea, su equitativa contraparte (p. 152).
\end{abstract}

También ocurre que cuando se enfatiza la nacionalidad de las fuerzas del orden lo que pasa a primer plano es el contrabando más que el comercio en sí, o sea burlar a las fuerzas de un país prepotente. Un ejemplo es el corrido «Pista enterrada», en donde un piloto burla a las autoridades confesando que trafica hierba mala y perdiéndose de vista. Pero no solo se pretende reivindicar al narcotraficante y sus subordinados sino a todos los mexicanos. Así, como quiera que sea, el narcotraficante es un buen mexicano.

Pero me gusta lo bueno se conforma así como un estudio ético, filosófico y discursivo de un género de la cultura popular sumamente extendido en México. Con su lectura, María Luisa de la Garza ha profundizado en un discurso tan criticado como popular, y que cada vez tiene más adeptos, tanto dentro como fuera de México — por los migrantes-. Así, la autora ha excavado hondo y mostrado que hay un complejo trasfondo social y semiótico en estas composiciones. A pesar de todo, no hay tantas diferencias entre los narcocorridos y los corridos de antes. Además, como se sugiere en la introducción: «habría que escuchar con más detenimiento no solo lo que estas canciones dicen de "ellos, los 
narcotraficantes", sino especialmente lo que dicen de "nosotros", los otros" que los juzgamos deleznables» (p. 8).

\section{Notas}

${ }^{1}$ Axel Honneth, La lutte pour la reconnaissance. Grammaire morale des conflicts sociaux, Éditions du Cerf, París, 2000, p. 122.

Fecha de recepción: 4 de noviembre de 2010.

Fecha de aceptación: 22 de marzo de 2011. 